\title{
UM PAÍs LAICo COM UM Governo TerrivelMente Cristão?
}

\author{
A LAY COUNTRY WITH A \\ TERRIBLY CHRISTIAN GOVERNMENT?
}

Gedeon Freire de Alencar *

"Não se trata de modernizar o cristianismo, e sim cristianizar a modernidade". (KEPEL, 1991, p. 87).

\begin{abstract}
RESUMO
No Brasil, desde o descobrimento em 1500 até o presente, sempre houve uma imbricação da politica e da religião, portanto, a grande novidade da atualidade é que temos um novo ator politico: os evangélicos pentecostais. O lema de campanha eleitoral e suas propostas tiveram, assim, uma adesão significativa desse campo religioso. Relacionaremos a história de poder e falência do Rio de Janeiro com o desenvolvimento e os problemas internos dos três maiores grupos denominacionais as Assembleias de Deus, Igreja Presbiteriana e Igreja Batista. O Rio de Janeiro falido precisa de uma intervenção militar, moral e divina? Idem, o Brasil? O novo governo é laico, mas como disse a Ministra Damares e também o próprio presidente: laico, mas terrivelmente cristão.
\end{abstract}

Palavras-chave: Protestantismo. Pentecostalismo. Governo Bolsonaro.

\begin{abstract}
In Brazil, since the discovery in 1500 to the present, there has always been an imbrication of politics and religion, so the great novelty of the present is that we have a new political actor: the Pentecostal evangelicals. The motto of the electoral campaign and its proposals had, therefore, a significant adhesion of this religious field. We will relate the history of power and bankruptcy of Rio de Janeiro with the development and internal problems of the three largest denominational groups, Assemblies of God, Presbyterian Church and Baptist Church. Does the bankrupt Rio de Janeiro need military, moral and divine intervention? Same, Brazil? The new government is secular, but as Minister Damares and the president himself said: secular but terribly Christian.
\end{abstract}

Keywords: Protestantism. Pentecostalism. Bolsonaro Government.

\section{INTRODUÇÃO}

O descobrimento do Brasil se deu em 22 de abril de 1500, oficializado por uma missa católica. A eleição do atual presidente se deu em 28 de outubro de 2018, oficializado quando o Tribunal Superior Eleitoral deu por encerrada a apuração dos votos. O eleito então surge via satélite com um grupo e, antes de falar, é feita uma oração pentecostal:

\footnotetext{
* Doutor em Ciências da Religião pela Pontifícia Universidade Católica de São Paulo (PUC São Paulo). Atualmente, é membro da Rede Latinoamericana de Estudos Pentecostais (RELEP), da Comissão de Estudos da História da Igreja na América Latina e Caribe (CEHILA) e do Grupo de Estudos do Protestantismo e Pentecostalismo (GEPP - PUC São Paulo). E-mail: gedeonalencar@gmail.com
} 
A missa foi em 1500, a oração pentecostal em 2018.

Mudou algo? "Tudo deve mudar para que tudo fique como está"1.

As afinidades eletivas (WEBER, 2014) ${ }^{2}$ entre política e religião não são uma invenção do "protestantismo tupiniquim" brasileiro (ALENCAR, 2018). Os faraós no Egito, os Césares em Roma, os reis medievais conjugaram, usaram e usufruíram dos dois poderes para benefício próprio. $\mathrm{E}$ desde quando não houve uma relação intrínseca de religião e política no Brasil? As caravelas portuguesas e a missa em 1500 são, além de uma ação política do império português, também uma demonstração clara e objetiva do poder político da Igreja Católica Apostólica Romana (ICAR). Desde o descobrimento passando pelo período do padroado no Império, são mais de 300 anos de uma religião com todos os direitos e privilégios. Na República, deixou de ser religião oficial, mas continuou por vias oficiosas. A Catedral na Esplanada dos Ministérios em Brasília se harmoniza em poder e beleza estética com os demais prédios estatais. Um dos maiores símbolos do Brasil no mundo é o Cristo Redentor, construído em 1930 e dado de presente à ICAR que ainda hoje administra e lucra na sua exploração turística. Contudo, a presença católica foi naturalizada. Há séculos é assim. O que parece assustar é esse novo ator político: o pentecostal.

Nada original, portanto, em nossa história, desde a colonização portuguesa, na sagração de Nossa Senhora de Aparecida como padroeira do Brasil, em 1930, no apoio que a ICAR e grupos evangélicos deram à Ditadura Militar (SCHMIDT, 2016), na Concordata com o Vaticano em 2010 (GIUMBELLI, 2011) até o atual governo, que essa simbiose político-religiosa esteja instrumentalizada. Retroalimentada. Mesmo que, às vezes, como no mundo antigo e também hoje esse seja um "abraço de afogados”, haja vista que essa relação promíscua, complexa e confusa produz muitos erros; e acertos, a depender do ponto de vista. Beneficiários ou perdedores em campos opostos, quando falam dos resultados ironicamente concordam.

Um pouco mais de atenção na movimentação do campo religioso e político nas últimas décadas nos indica que algumas "peças" foram trocadas, mas o tabuleiro continua igual. A “originalidade" do momento é o atual presidente falar do grupo, a imprensa divulga quase diariamente algo sobre o tema, e até se tornou tema até na academia - por

${ }^{1}$ Frase do Príncipe Falconeri, na obra “O Leopardo”, de Giuseppe Tomasi de Lampedusa (1896-1957).

2 Como diria Weber (2014, p. 83) “certas formas de fé religiosa e certas formas de ética profissional” podem ter resultados inter-relacionados que não originalmente seus objetivos. 
que exatamente eles, os pentecostais, não iriam acreditar que estão no centro do poder? Mas, esse fenômeno social é bem mais complexo.

Entender historicamente o campo religioso evangélico fluminense (e também católico, mas iremos privilegiar em nossa análise o primeiro) pode nos dar algumas pistas. A falência institucional das religiões, o caos administrativo do Estado e a perda de importância política econômica da região são, intercaladas, origens, sintomas e consequências. O Rio de Janeiro, cidade e estado, como um microcosmo brasileiro, é a representação - ou o resultado - dessa história. Falido, precisa de uma intervenção externa, moral, urgente, militarizada e autoritária. O Brasil, idem. Então surge a indagação paradoxal: o Brasil se tornou mais conservador pela presença evangélica na política ou exatamente por ser conservador é que os políticos evangélicos tiveram espaço para crescer?

\section{O CAMPO POLÍTICO E RELIGIOSO DO RIO DE JANEIRO}

A incidência evangélica na política brasileira é remédio ou veneno? (ALENCAR, 2015) Ela é visível a partir da década de 1980 no legislativo e foi motivada pela Constituinte de 1988 (FRESTON, 1993; BAPTISTA, 2009; CAMPOS MACHADO, 2013), mas no Rio de Janeiro essa incidência é mais antiga e se deu também no executivo. Lá já se elegeram cinco governadores evangélicos, embora eles não tenham sido eleitos unicamente por serem evangélicos. Se a membresia religiosa não ajudou diretamente o fato é que também não impediu. Percebe-se, portanto, que o estereótipo da instrumentalização evangélica na política precisa de alguma relativização, pois sua existência não é o que há de pior, como os inimigos insistem em afirmar, mas também está longe de ser uma panaceia, como rezam os interessados. "Nem anjos, nem demônios" (ANTONIAZZI, 1994). Ademais, se a presença evangélica foi e é significativa na Câmara Federal com mais de 70 deputados federais e 2 senadores eleitos em 2018 eleitos, alguns presumivelmente batistas 3 , o executivo continua sendo um palco dessa atuação, visto que, como já dito, cinco exgovernadores do Rio de Janeiro eram evangélicos e o atual prefeito é um bispo licenciado da IURD.

\footnotetext{
3 Flavio Bolsonaro (PSL), 37 anos e no quarto mandato de deputado estadual, foi eleito com 4.380.418, equivalente a 31,36 dos votos válidos, e Arolde de Oliveira, 81 anos, foi deputado federal por nove mandatos, foi o segundo senador eleito, com 2.382.265 votos, ou seja, 17,6\% dos votos válidos.
} 


\section{Tabela 1 - Governadores evangélicos no Rio de Janeiro}

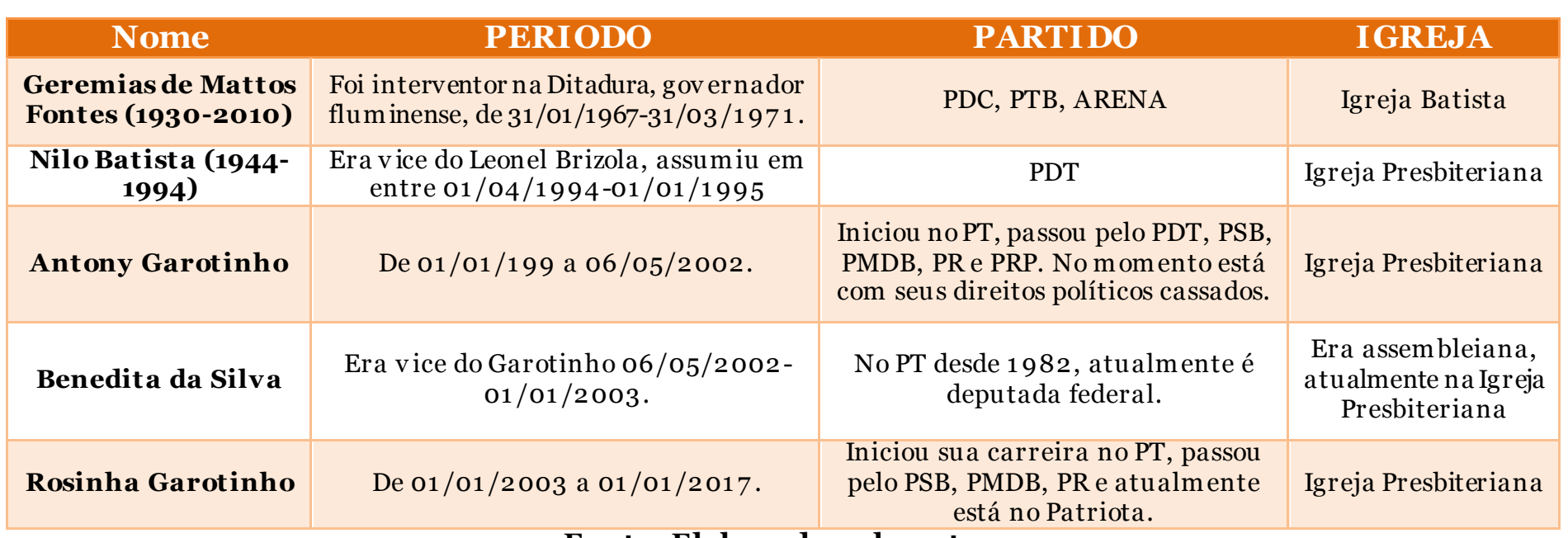

Fonte: Elaborado pelo autor.

Sintomático que essa presença no Executivo seja representativa da incidência política dos evangélicos de igrejas clássicas reformadas, o grupo pppp - pobres, pretos, periféricos e pentecostais - tem algum protagonismo apenas no legislativo. E nenhuma coincidência que figuras como Geisel, Fanini, Geremias, Garotinho pertençam ao protestantismo clássico reformado, elitizado, branco, rico, urbano, militar, masculino e de direita4, e figuras como Benedita representem o pentecostalismo, rural, pobre, favelado, feminino e de esquerda (CESAR; SHAULL, 1999, p. 106-107). E, novamente, nenhuma coincidência quando esse grupo pppp de alguma forma alcance o poder somente quando alguns - e somente alguns - têm ascensão social!5

O Rio de Janeiro foi o primeiro alvo protestante com a chegada dos huguenotes em 1557, mas, como a presença protestante holandesa no Nordeste em 1630, sem nenhum resultado religioso ${ }^{6}$. No Censo de 2010, a cidade do Rio de Janeiro tinha $51 \%$ de católicos, 23,37\% de evangélicos e 13,59\% sem religião. O Rio de Janeiro foi o estado brasileiro com o maior decrescimento católico ${ }^{7}$ e o percentual sem religião, espiritas e cultos afro revelou-

\footnotetext{
4 Sobre a participação de igrejas protestantes no apoio a Ditadura ver Schmidt (2016) e Leonildo Campos (2002), e o clássico texto do Rubem Alves lançado em 1979, Protestantismo e Repressão, e relançado em 2005 com alteração do nome para Religião e Repressão,

5 Como na elite brasileira, é um grupo pequeno de pentecostais nes se estrato. Como já aconteceu comigo mais de uma vez em conversas com pessoas na acadêmica: "Mas você é pentecostal e está fazendo doutorado?" E eu respondia: "Mas você está doutorado e faz essa pergunta?"

${ }^{6} \mathrm{Na}$ historiografia brasileira, a chegada dos portugueses em 1500 é registrada como "descobrimento", já a chegada dos franceses e holandeses como "invasão".

7 Que não é um fenômeno exclusivo do RJ ou do Brasil, mas da AL (Joao Luiz) e do mundial segundo o Instituto de Pesquisa PEW (2014). Disponível em: <https://oglobo.globo.com/brasil/rio-estado-commenor-percentual-de-catolicos-revela-censo-2010-5345770 >.
} 
se maior do que a média nacional ${ }^{8}$. Nas regiões metropolitanas, há o que o Atlas da Religião (JACOB, 2003) chamou de "Anel Pentecostal”, onde os índices católicos são menores e o de evangélicos e os s/r, maiores9. Se a ICAR é ainda o "doador universal" (ALMEIDA, 2004, p. 18), a porta de saída tanto de católicos como de evangélicos, no Rio de Janeiro, é essa condição anódina dos "sem religião"? Diversos autores já indicaram que a taxa de crescimento do s/r é maior nos espaços de domínio religioso evangélico.

Fica evidente uma tendência de que os sem religião tenham vindo do mundo evangélico. Pessoas criadas católicas parecem ter passado por igrejas evangélicas antes de optar por ficar sem religião. Esses dados são coerentes com o fato de que, segundo o censo, se observa uma similaridade entre $o$ perfil social dos sem religião e o dos ev angélicos, e também para o fato de que cidade e estados com maior proporção de evangélicos são os que têm maior proporção de sem religião (MARIZ, 2013, p. $56)$.

Pesquisa da Secretaria de Educação em Ferraz de Vasconcelos, em 2017, com o corpo discente da cidade, encontrou os seguintes índices: Evangélicos 49,82\%, católicos 25\% e "sem religião, mas crendo em Deus" 22,81\% (MARQUES, 2019, p. 118).

\section{O CAOS INSTITUCIONAL DAS DENOMINAÇÕES EVANGÉLICAS CARIOCAS.}

O Rio se tornou capital do país em 1763, mas nas últimas décadas daquele século perdeu importância e poder para São Paulo. O quadro abaixo mostra apenas o crescimento populacional das duas cidades, mas também é indicio claro de como São Paulo ultrapassou o Rio de Janeiro nas questões econômicas e culturais.

\section{Tabela 2 - Brasil: População segundo as capitais (1872/1940)}

\begin{tabular}{|c|c|c|c|c|c|c|c|c|c|}
\hline & 1872 & 1890 & 1900 & 1920 & 1940 & 1960 & 1980 & 2010 \\
\hline $\mathbf{R J}$ & 274.972 & 522.651 & 811.443 & 1.157 .873 & 1.764 .141 & 3.307 .163 & 5.183 .992 & 6.520 .266 \\
\hline $\mathbf{S P}$ & 31.385 & 64.934 & 239.820 & 579.033 & 1.326 .261 & 3.825 .351 & 8.587 .665 & 11.253 .503 \\
\hline
\end{tabular}

Fonte: Censos IBGE

${ }^{8}$ Católicos 51 \%, Evangélicos 23,37\%, S/R 13,59\%, Espíritas 5,9\% e cultos afro 1,29\% - Censo 2010.

9. Já o Rio de Janeiro passou a liderar o processo de transição religiosa. Por exemplo, três grandes municípios que já apresentaram mudança na hegemonia religiosa, em 2010, foram Nova Iguaçu (com 796 mil habitantes) que apresentou uma percentagem de 33\% de ca tólicos, 36,9 de evangélicos e 21,2\% de sem religião; Duque de Caxias (com 855 mil habitantes) estava com 35\% de católicos, 36,8\% de evangélicos e $20,3 \%$ de sem religião; e Belford Roxo (com 469 mil habitantes) que apresentou 32,5\% de católicos, 37,1\% de evangélicos e 22,7\% de sem religião municípios com maioria evangélica, em especial cidades grandes como Duque de Caxias, Nova Iguaçu e Belford Roxo (os vinte municípios fluminenses com maioria evangélica tinham uma população total de 3,5 milhões de habitantes em 2010). 
No quesito religião não seria diferente tanto no campo católico como no protestante, e apesar de não estarmos tratando dos grupos neopentecostais neste texto, é sintomático o fato que a IURD e a IIGD tenham iniciado seus projetos no Rio, e que posteriormente transferiram suas sedes para SP, e nos últimos anos todos os maiores e midiáticos grupos neopentecostais surgiram exatamente em SP. No espaço católico do Rio de Janeiro, nenhum outro líder teve a importância e força como teve o Cardeal Leme (1882-1942) na década de 1930.

Vamos centrar nossa análise em três grupos protestantes: assembleianos, batistas e presbiterianos. Todos esses grupos tiveram líderes carismáticos (WEBER) que, mimetizados, fizeram o rebanho evangélico explodir; midiáticos, surfaram nesse crescimento, transcenderam suas denominações no Rio e no Brasil; embora também controversos, desapareceram, perderam o carisma e alguns caíram em desgraça, de forma que acabaram contribuindo para a bancarrota denominacional.

Os nomes assembleianos mais conhecidos nos últimos anos no Rio de Janeiro foram Tulio Barros, das ADs - Ministério de S. Cristóvão, Marcos Pereira, das Assembleias de Deus dos Últimos Dias - ADUD, e Silas Malafaia, das Assembleias de Deus Vitória em Cristo-ADVC. Tulio Barros, pastor da AD S. Cristóvão (a AD mais rica e moderna no Rio de Janeiro em seus tempos áureos), liderou um projeto de alfabetização nacional nos anos 1980, o ALFALIT, e se tivesse sido de fato implementado no país teria feito uma enorme e positiva alteração social. Marcos Pereira, pastor das ADUD, se tornou um fenômeno pelas intervenções milagrosas nos presídios, e por seu discurso do "resgate" do mais extremo conservadorismo e "pureza” da doutrina; Silas Malafaia, pastor das ADVC, é um exemplo ímpar de modernização, pois tinha seu programa de TV quando as ADs ainda satanizavam a televisão. O surgimento deles - e muitos outros parecidos no Rio de Janeiro e restante do país - mostra que as ADs estão irreversivelmente marcadas pela luta fratricida da “ministerialização" (FAJARDO, 2018). Eles são exemplos dos modelos de assembleianismo difuso e autônomo (ALENCAR, 2013), pois instrumentalizaram a franquia assembleiana (CORREA, 2013), surfam na pluralização e aggiornamento pentecostal (COSTA, 2018) e, no final, como são absolutamente personalíssimos, acabam sendo os próprios beneficiários. Tulio Barros não emplacou seu projeto, se tornou bispo, saiu da CGADB e sua igreja se neopentecostalizou. Marcos Pereira foi preso e condenado por denúncias de exploração sexual e tráfico de drogas, e Malafaia coleciona polêmicas e denúncias, e se notabilizou pela falastronice e pelos inimigos internos e externos na denominação. 
No meio batista, desde a década de 1950, o pastor Nilson Fanini (1932-2009) foi o considerado o "Billy Graham brasileiro". Um dos pioneiros midiáticos, dono de canal de TV, presente pelo apoio que deu à Ditadura ${ }^{10}$, foi pastor da PIB de Niterói por 41 anos e alcançou projeção internacional como presidente da Aliança Batista Mundial (19952000), mas terminou seu ministério de forma sofrível com denúncias de corrupção ${ }^{11}$. Depois dele nenhum pastor batista ou mesmo a denominação usufruiu de igual protagonismo.

No campo presbiteriano, nas décadas de 1980 e 1990, Caio Fabio foi uma figura central. Amazonense, centralizou seu ministério no Rio de Janeiro. Manteve uma revista nacional, um canal de TV, um megaprojeto social, editora, congressos e, dono de grande carisma, consegui agregar na Associação Evangélica Brasil (AEVB). Depois do projeto de alfabetização nacional que a Confederação Evangélica Brasileira-CEB teve nos anos 1940, nunca mais os evangélicos brasileiros tiveram, em unidade, algum projeto para o país como teve Caio Fabio e a Associação Evangélica Brasileira (AEVB)12 ${ }^{2}$ Apesar disso ele também faliu. Personalístico e grandiloquente terminou de forma melancólica por problemas pessoais e institucionais. Por conseguinte, o modelo "progressista" presbiteriano e evangélico teve como resultado uma grande reação conservadora.

A Presbiteriana, apesar de seis grupos denominacionais distintos ${ }^{13}$, ainda mantém alguma uniformidade em cada um deles. Já os batistas, pela sua natureza local, autônoma e anárquica, apresentam um degradê de um extremo ao outro. Há batistas para todos os gostos - e desgostos. No universo assembleiano, pela imensidão do campo e pluralidade dos assembleianismos (ALENCAR, 2013), os nomes e problemas - antes e depois - são muitos mais complexos. Mas podem existir até assembleias que são de Deus.

O mundo ideal protestante ortodoxo, na expressão de Rubens Alves (1979), o chamado "protestantismo da reta doutrina”, foi substituído pela barganha cósmica; da incidência pública com atuação de transformação social, pelo adesismo político; do fortalecimento institucional, pela anárquica pluralização; de presença internacional e

\footnotetext{
10 Ganhou a concessão da TV Rio e seu programa "Reencontro" era exibido em mais de cem canais no Brasil e também nos EUA.

${ }_{11}$ Eclésia - a revista evangélica brasileira, ano 10, no, 142, 2004.

12 A CEB foi criada em 1934 e foi e desarticulada na Ditadura Militar. A AEVB nasceu em 1991, mas devido à centralidade personalística de seu fundador e presidente, Caio Fabio, morreu por inanição. Em 2010, algumas lideranças evangélicas articularam uma nova instituição, a Aliança Cristã Evangélica Brasileir a, ainda longe de ser o que foram, em suas épocas e por razões distintas, a CEB e a AEVB. https://www.aliancaevangelica.org.br/

13 No Brasil, no momento, existem oficialmente 7 grupos presbiterianos, a Igreja Presbiteriana do Brasil (1865), Independente (1903), Conservadora (1940), Fundamentalista (1956), Independente Renovada (1972), Renovada (1968) e Unida (1978).
} 
nacional, pela luta fraticida de poder; de um projeto civilizatório de educação moderna, por um mimetismo canhestro de um Talibã gospel?14; de incidência social direto para as páginas policiais. Enfim, o projeto triunfalista de "salvar o pais" foi substituído pelo “cristofascismo" (PY, 2018), no plano macro e no micro, na infame ação de "traficantes evangélicos” (MARQUES, 2014, 2019; MEDRADO, 2015), que ainda não destruiu o pais, mas está quebrando espaços sagrados dos cultos afro com displicência das autoridade e a implícita anuência dos grupos evangélicos!

As instituições evangélicas cariocas faliram? Também. Em resumo, tivemos projetos arrojados, modernos, com figuras de expressão nacional e internacional fazendo do espaço do Rio de Janeiro a principal campo religioso brasileiro, porém tais figuras e seus projetos faliram e foram substituídos por figuras e projetos reacionários e moralistas. Nessa vacuidade de projetos e desinstitucionalização denominacional é que surgem figuras midiáticas e folclóricas, tanto na política como na religião, que agregam, instrumentalizam, se fortalecem e antropofagicamente se destroem. Faliram no Rio de Janeiro e faliram no país inteiro (e a falência não foi somente das instituições religiosas), por isso é fácil entender como um candidato sem projeto de país é eleito e celebrado por um grupo que, igualmente, não tem um projeto para o país. Os cinco ex-governadores evangélicos não conseguiram destruir o Rio de Janeiro, os dois governadores católicos seguintes estão presos, e o atual, um juiz, se diverte em um helicóptero dando tiros em tendas de oração.

\section{JAIR MESSIAS BOLSONARO - A CARICATURA DO MESSIAS}

Como e por que um deputado federal carioca, por 27 anos, membro do "baixo clero", que raras vezes se pronunciou na Câmara Federal, defensor da família tradicional, mas divorciado pela terceira vez; católico, mas batizado por um pastor assembleiano no Rio Jordão; expoente da moral cristã, mas propagador de vídeos pornográficos; contra o Brasil ser um paraíso gay, mas incentiva estrangeiros a abusarem das mulheres; opositor da educação sexual, mas a favor de que crianças possam aprender a usar armas; com discurso de segurança, mas que como parlamentar fluminense nunca contribui para a causa, como esse homem conseguiu apoio e adesão da maioria dos católicos e evangélicos no Brasil?

\footnotetext{
14 Ministério para a Promoção da Virtude e Prevenção do Vício ${ }^{14}$, Taleban no Afeganistão, função: verificar quem está ouvindo música, as barbas dos homens e o cortes de cabelos das mulheres e, se for necessário, empunhados com bastões em mãos para açoitar publicamenteos infratores https://www1.folha.uol.com.br/mundo/2015/o8/1671525-distrito-afegao-exemplifica-vida-sob-governotaleban.shtml acesso 21.91.2019.
} 
Na vacuidade, a força; na nulidade, o poder; no caos, a ordem. Óbvio e convincente - para quem já está convencido.

\begin{abstract}
A grande tarefa da Igreja é a reform a do m undo - dar fim a todo o tipo de pecado. A Igreja foi organizada originalmente para ser um corpo de reformadores. A própria tarefa do cristianismo implica na tarefa e virtualmente no compromisso de fazer tudo o que estiver ao seu alcance para a reforma do mundo. A Igreja cristã foi designada para fazer movimentos avançados em todas as direções - levantando sua voz e pondo toda sua energia nos lugares altos e baixos - para reform ar indivíduos, com unidades e governos (grifo nosso).
\end{abstract}

Não é a política que vai mudar essa nação, é igreja (grifo nosso)

A primeira citação acima são palavras de Charles Finney (1792-1875), pregador avivalista americano, em 21/01/1846 15 ; já a segunda frase foi dita por Damares Alves, advogada e atual ministra dos Direitos Humanos, em uma palestra numa igreja no Mato Grosso, em 2013 ${ }^{16}$. O contexto do Finney é sua luta contra a escravatura, o da ministra é sua luta contra a "ideologia de gênero" e o feminismo. Essa pretensão de superioridade moral da Igreja - seja ela qual for - sempre existiu, o que mudou foi o contexto.

“O Brasil acima de tudo. Deus acima de todos”.

Brasil acima de tudo? Tudo é muita coisa. Ademais, nenhuma novidade, já que sempre existiu um "Brasil acima de tudo". "Seis brasileiros - todos homens brancos concentram a mesma riqueza que a metade mais pobre da população, mais de 100 milhões de pessoas. E os 5\% mais ricos do país recebem por mês o mesmo que os demais $95 \%$ juntos"17, pesquisa sobre os níveis de desigualdade social no Brasil.

O lema já indica, a priori, duas violações de direitos. Primeiro dos ateus e agnósticos, pois eles terão que, por imposição estatal, se curvar. Segundo, ironicamente, dos próprios crentes - de todos os crentes cristãos, hindus, muçulmanos e afro. Deus? Qual Deus? Esse filme já vimos algumas vezes: Constantino transformou o cristianismo em religião oficial e o resultado não foi dos melhores, e a experiência de países mulçumanos também não ajuda nessa resposta. Mas ateus e agnósticos no Brasil representam menos de

\footnotetext{
15 Citado por Dayton (2018, p. 265).

16 https://politica.estadao.com.br/noticias/geral,nao-e-a-politica-que-vai-mudar-esta-nacao-e-a-igreja-dizdamares-

alves,70002636241https://www.correiobraziliense.com.br/app/noticia/politica/2018/12/o7/interna_polit ica,7 23913/nao-e-a-politica-que-vai-mudar-esta-nacao-e-a-igreja-diz-damares-alves.shtml acesso 12.01.2019.

17 https://www.oxfam.org.br/os-numeros-das-desigualdades-no-brasil
} 
$1 \%^{18}$, a democracia, afinal, não é a ditatura da maioria, como indicou Tocqueville? Se a maioria decidiu, a minoria que se adeque. Não é isso que estamos ouvindo?

Não deu certo com Constantino em Roma, com a nobreza protestante europeia (FEBVRE, 2012, p. 56), ou com as repúblicas islâmicas. Ou deu. Ou dá certo quando se trata de uma religião hegemônica, despótica e ditatorial, e essa privilegia um grupo em detrimento dos demais, legitimando assim absolutas violações de direito.

Problema interno da maioria cristã: Deus? Qual? Para os católicos, em tese, é "fácil" resolver pois, a ICAR em sua teologia magisterial, com milênios de prática de hegemonia, os resquícios da Inquisição ainda vigentes, e com a clara e bem definida delimitação entre clero e laicato, todos sabem seus lugares. Afinal, a fala oficial tem a prerrogativa da infalibilidade. E, no caso, nem Deus pode mudar o que a Igreja já determinou. Parodiando Florestan Fernandes em sua ironia de que no Brasil não existe racismo porque os negros conhecem seu lugar, poderíamos dizer que no catolicismo não há tensão porque leigos católicos conhecem seus lugares.

Já no protestantismo é o “samba do teólogo doido". É o Deus calvinista soberano que, de antemão, excluí e salva esses e não aqueles? Ou seria o Deus arminiano que quer salvar todos, mas deixa que eles mesmos decidam se aceitam ou não essa salvação? É o Deus que criou os gêneros igualitários e com a mesma dignidade? Ou o Deus que legitima a negação de direitos às mulheres, ignora os negros, abomina os gays, esquece-se dos índios, distribuí bênçãos aos ricos e aos pobres apenas resignação? Ora, cada igreja protestante celebra uma faceta desse divino; mais ainda, cada protestante evangélico pentecostal - e há uma infinidade de designações adjetivas - celebra algo distinto do outro. Cada um celebra, aliás, seu Deus individualmente ${ }^{19}$. A clássica oração ensinada por Jesus fala em “pai nosso [...] pão nosso [...] nossas dívidas”, e aqui parece que teremos que lamentar, pois ele, parece, errou o pronome.

“Deus acima de todos?” Se for o meu Deus, sim. Principalmente, por que, assim eu e ele - estaríamos acima de todos...

\footnotetext{
18 Censo de 2010. População geral 190.755.799, S/R - 15·335.5120, ou 8.04\%, ateus são 615.096, ou 03,2\% e agnósticos 124.436.

19 Os cânticos protestantes evangélicos pentecostais, e mais acentuadamente os neopentecostais são exemplar nisso: são sempre na primeira pessoa. "Meu Deus, minha casa, minha benção".
} 


\section{ESCATOLOGIA: UMA DOUTRINA POLITIZADA}

O presidente se batizou no Rio Jordão, mas continua se apresentando como católico. Dessa forma ele comete dois pecados: menospreza seu batismo católico infantil e ridiculariza o batismo evangélico adulto por imersão. Foi apenas uma brincadeira de um candidato e um pastor fazendo marketing político? E, absurdamente, nem a Igreja Católica nem os evangélicos que o apoiam se manifestam sobre esse fato.

Na posse da Ministra Damares, ela e seu grupo gravaram um vídeo-metáfora onde estabelecem um dos parâmetros do seu ministério: meninos vestem azul e meninas vestem rosa. O vídeo viralizou e no início da cena há uma pessoa ao lado com uma bandeira de Israel. Aliás, bandeira muito usada na Marcha para Jesus e nos púlpitos das igrejas atualmente. Para não acusarmos de que a única pauta evangélica com embasamento teológico-político seja apenas moralismos, existe o tema da transferência da capital de Israel para Jerusalém. Essa marca escatológica é central em toda a história protestante no Brasil, e essa escatologia indica explicitamente que ela nasce no paradigma de "Israel como relógio de Deus”. Não vou discutir teologia, mas - sem entrar no mérito de certo ou errado - a pergunta é: qual a importância, validade e alteração que a mudança da capital de Israel faria ou fará na estiagem do Nordeste, na elevação ou queda do nível de escolaridade dos brasileiros, nos índices de violência urbana e na (imoral) estatística de feminicídios? Ou seja, o principal e quase único projeto evangélico político não tem nenhuma resposta para nossas questões urgentes. Não há projeto para o Brasil, mas muita energia gasta em um projeto para Israel!

\section{CONSIDERAÇÕES FINAIS}

Vai dar certo ou vai dar errado? Já deu certo e também já deu errado - basta perguntar para os apoiadores e inimigos, ambos têm certeza. Algumas afirmações para concluirmos.

1. Gilles Kepel, no seu livro de A Revanche de Deus, analisando o rejuvenescimento islâmico, judaico e cristão, ao analisar a ascensão da direita cristã nos EUA diz que o objetivo não era "modernizar o cristianismo, e sim cristianizar a modernidade” (KEPEL, 1991, p. 87). No Brasil, ainda estamos mais longe, pois temos uma "modernidade arcaica” ou, como diz Moreira (1999, p.199), temos 
“modernização sem modernidade”20. Fácil criticar os evangélicos, ainda mais os pentecostais, haja vista que à luz de certos artigos da imprensa e textos da academia a impressão que temos é que a nação inteira é um Canadá de multiculturalismo, uma Holanda de tolerância e uma Suécia de liberdade, se não fosse a presença conservadora dos pentecostais.

2. Os pentecostais querem instrumentalizar o Estado? Também. Nada diferente do que a Igreja Católica faz há séculos, inclusive, na assinatura da Concordata com o Vaticano assinada pelo então Papa Bento XVI e o presidente Lula, em 2010. Não existe um projeto de poder dos evangélicos, mas uma tentativa de instrumentalização de algumas figuras e de alguns grupos. Se existe algo que define a natureza protestante evangélica é a cissiparidade, o dissenso. A absoluta falta de unidade em tudo e em todos. Cada grupo diz algo que o outro grupo discorda; cada figura carismática representa uma ideia que a outra figura carismática abomina; cada proposta de um determinado grupo entra em concorrência frontal com o interesse do outro, e assim vamos. Portanto, nunca vai existir um projeto político único, homogêneo e coeso dos evangélicos para o país (GUADALUPE, 2018).

3. Os pentecostais são adesistas políticos? E os bancos e as grandes fortunas desse país? Não estamos lidando com os valores do evangelho de Jesus ${ }^{21}$ - (fome e sede Justiça, Mt. 5:6), mas lidando com interesses de grandes conglomerados financeiros, necessidades de canais de TV, objetivos concretos de editoras, gravadoras, etc. Para isso é necessária a articulação dos canais políticos e das manobras políticas partidárias. Por que a Frente Parlamentar Evangélica apoiou o FHC, depois o Lula, depois a Dilma, esteve na posse do Temer e agora majoritariamente apoia o presidente eleito? Porque a FPE representa interesses que precisam de respostas efetivas de quem detém o poder - seja de esquerda, seja de direita. É o uso instrumental do poder - e aqui não estamos fazendo juízo de valor. O poder tem poder. E esse poder existe para ser usado. Raimundo

20 Moreira (1999) em seu tex to “Weber o mal-estar colonial”, diz que desde a colônia o Brasil tem incentivo e preocupação da modernização tecnológica, mas com “adoção acrítica de ideias estrangeiras; o bacharelismo e a cultura ornamental; o autoritarismo; a democracia como equívoco; a confusão entre as esferas pública e privada, e a mudança pelo alto e a modernização sem modernidade”.

21 "Porque tive fome, e vocês me deram de comer; tive sede, e vocês me deram de beber; eu era forasteiro, e vocês me hospedaram; eu estava nu, e vocês me vestiram; enfermo, e vocês me visitaram; p reso, foram me ver" Mt. 25:35-36. 
Faoro, no clássico "os donos do poder”, diz que "assim é porque sempre foi”. Os pentecostais são uma ameaça à laicidade democrática? E a cruz no STF, o Cristo Redentor e 012 de outubro consagrado à Padroeira do Brasil não são?

4. Os pentecostais são misóginos? Também. Mas de forma muito mais branda do que a Igreja Católica e as igrejas tradicionais reformadas e presunçosamente cultas. Machismo não é privilégio dos pentecostais ${ }^{22}$. Em quais instituições desse país mulheres negras, pobres e analfabetas têm espaço para cantar, orar, pregar e exercer alguma liderança senão em igrejas pentecostais periféricas?

5. A esquerda foi e ainda é preconceituosa com religião, especialmente com evangélicos, e mais acentuadamente com pentecostais. Com seu ranço positivista, sua petulância intelectual e sua falsa exclusividade ética (que foi desmentida nos inúmeros escândalos de corrupção) nunca deu atenção ao grupo pppp. E, nesse momento, alguns grupos e pessoas somente estão dando atenção porque perderam a eleição - o Haddad falou disso numa entrevista para a Folha ${ }^{23}$.

Concluo com uma das pérolas da ministra Damares Alves: "Esse país é laico, mas essa ministra é terrivelmente cristã ${ }^{24 "}$. Dos três adjetivos usados, ainda tenho muitas dúvidas acerca do laico e do cristã, mas o terrível me soa bem convincente.

\section{REFERÊNCIAS}

ALENCAR, Gedeon. Matriz Pentecostal Brasileira: Assembleias de Deus 1911-2011, São Paulo, Editora Recriar, 2018.

ALENCAR, Gedeon. Presença evangélica no Brasil atual: remédio ou veneno? Observatório da Religião, UEPA, v. 2, n. 2, 2015, p. 130-152.

\footnotetext{
22 A IP Pinheiros promoveu um IX Congresso Plantação \& Revitalização de Igrejas. Discipulando Mulheres e as novas gerações ${ }^{22}$ com cinco preletores homens. Otítulo e o modelo são óbvios: homens discipulando as mulheres do presente e as novas gerações. Pois, parece, na IPB, também todos sabem seus lugares.

23 https:// www1.folha.uol.com.br/poder/2018/11/elite-economica-abriu-mao-de-seu-verniz-ao-elegerbolsonaro-diz-haddad.shtml

24 https://istoe.com.br/o-estado-e-laico-mas-essa-ministra-e-terrivelmente-crista-diz-damares-alves/
} 
ALENCAR, Gedeon. Protestantismo Tupiniquim: hipóteses sobre a (não) contribuição protestante à cultura brasileira, São Paulo, Editora Recriar, 2018.

ALENCAR, Gedeon; FAJARDO, Maxwell. Pentecostalismos: uma superação da discriminação racial, de classe e de género. Estudos da Religião - Revista da UMESP, São Paulo, v. 30, n. 2, p. 95-112, mar./ago. 2016.

ALMEIDA, Ronaldo. Religião na Metrópole Paulista. In: Revista Brasileira de Ciências Sociais, v. 19, n. 56, out. 2004, p. 15- 27.

ALVES, Rubem. Protestantismo e repressão. São Paulo: Ática, 1979.

ANTONIAZZI, Alberto (org.). Nem anjos nem demônios: interpretações sociológicas do pentecostalismo. Petrópolis: Vozes, 1994.

AZEVEDO, Israel. A celebração do Indivíduo. Piracicaba: UNIMEP, 1996.

BAPTISTA, Saulo. Pentecostais e Neopentecostais na Política Brasileira: um estudo sobre a cultura política, Estado e atores coletivos religiosos no Brasil. São Paulo: Annablume, 2009.

BERGER, PETER: Os múltiplos altares da modernidade. Rio de Janeiro: Editora Vozes, 2017.

BOURDIEU, Pierre. A economia das trocas simbólicas. São Paulo: Perspectiva, 1974.

CAMPOS, Leonildo Silveira. Protestantes na primeira fase do regime militar brasileiro: atos e retórica da Igreja Presbiteriana Independente do Brasil (1964-1969). Horizonte: revista de Estudos de Teologia e Ciências da Religião (Online), Belo Horizonte, v. 23, n.1, p. 95-156, 2002.

CAMPOS MACHADO, Maria das Dores (org). Os votos de Deus: evangélicos, política e eleições no Brasil. Recife: Massangana (Fundação Joaquim Nabuco), 2013.

CAMPOS, Leonildo Silveira. Teatro, templo e mercado: organização e marketing de um empreendimento neopentecostal. São Paulo: UMESP; Vozes, 1999.

CESAR, Waldo; SHAULL, Richard. Pentecostais e o futuro das religiões cristãs. Petrópolis: Vozes, 1999.

CORREA, Marina A.O.S. A operação do carisma o exercício do poder: a lógica dos ministérios das igrejas Assembleias de Deus no Brasil. São Paulo: Recriar, 2018.

COSTA, Moab C. C. O aggiornamento do pentecostalismo brasileiro: as Assembleias de Deus e o processo de acomodação a sociedade de consumidores. São Paulo: Recriar, 2018.

DAYTON, Donald. Raízes Teológicas do Pentecostalismo. Natal: Carisma, 2018. 
FAGUNDEZ, Ingrid. Bolsonaro: a infância do presidente entre quilombolas, guerrilheiros e a rica família de Rubens Paiva. BBC News Brasil. 16 jan. 2019. Disponível em: https://www.bbc.com/portuguese/brasil46845753?ocid=socialflow_facebook\&fbclid=IwAR2uHCuyoOW6ritpm_v8y_DykHBvHS 429HtzyUnrzaQGQ6fpBUQv56F3kOI. Acesso em: 29 abr. 2019

FAJARDO, Maxwell. Onde a luta se travar: uma história das Assembleias de Deus no Brasil. Curitiba: Primas, 2016.

FEBVRE, Lucien. Martinho Lutero, um destino. São Paulo: Três Estrelas, 2012.

FERNANDES, Rubem César (Org.). Novo nascimento: os evangélicos em casa, na igreja e na política. Rio de Janeiro: Maud/ISER, 1998.

FRESTON, Paul. Protestantes e Política no Brasil: da constituinte ao impeachment. 1993. Tese (Doutorado em Ciências Sociais) - Universidade Estadual de Campinas, Campinas, 1993. $307 \mathrm{f}$.

GIUMBELLI, Emerson. Marcos Legislativos de Regulação do Religioso no Brasil: Estatuto da Igualdade Racial, Acordo Brasil-Vaticano e Lei Geral das Religiões. Numen: revista de estudos e pesquisa da religião, Juiz de Fora, v.19 n.2, 2016, p. 65-85. Disponível em: https://periodicos.ufjf.br/index.php/numen/article/view/22067. Acesso em: 16 ago. 2019.

JACOB, C. et al. Atlas da filiação religiosa e indicadores sociais no Brasil. Rio de Janeiro/São Paulo: Ed. PUC-Rio/Loyola, 2003.

KEPEL, Gilles. A Revanche de Deus: cristãos, judeus e mulçumanos na conquista do mundo. São Paulo: Siciliano, 1991.

MARIZ, Cecilia. O que precisamos saber sobre o censo para falar sobre os seus resultados: um desafio pra novos projetos de pesquisa. Debates do NER - UFRGS, Porto Alegre, v. 14, 2013, p. 39-58.

MARQUES, Vagner. Fé e Crime: evangélicos e PCC nas periferias de São Paulo. São Paulo: Fonte Editorial, 2015.

MEDRADO, Lucas. Cristianismo e criminalidade: adesão de bandidos ao universo cristão pentecostal. São Paulo: Fonte Editorial, 2015.

MENDONÇA, Antônio Gouvêa Filho; VELASQUES, Prócoro. Introdução ao Protestantismo no Brasil. São Paulo: Loyola, 1990.

MOREIRA, Roberto S.C. Weber e o mal estar colonial. In: SOUZA, Jessé de (Org.) 0 malandro e o protestante: a tese weberiana e a singularidade cultural brasileira. Brasília: Universidade de Brasília, 1999.

SCHMIDT, Daniel. Protestantismo e Ditadura Militar. São Paulo: Fonte Editorial, 2016.

SOUZA, Jessé (Org.) O protestante e o malandro: a tese weberiana e a singularidade brasileira. Brasília: UNB, 1999. 
WEBER, Max. Economia e Sociedade. 4 ed. Brasília: UNB, 1998.

WEBER, Max. A ética protestante e o espirito do capitalismo. São Paulo: Cia das Letras, 2014.

Recebido em: 29.05.2019

Aprovado em: 13.07.2019 